\title{
Costs and Risks in neonatal pharmacology
}

\author{
Shalini Sri Ranganathan
}

Children are not small adults, infants are not just small children and neonates are not small infants. This is not a part of a poem, but an outcry from handful of paediatric and perinatal clinical pharmacologists which set off many changes in paediatric and neonatal therapeutics in the recent past.

For obvious reasons, advances in paediatric clinical pharmacology have outpaced advances in neonatal clinical pharmacology prompting the neonatal clinical pharmacologists to protest that "newborns were one of the last therapeutic orphans to be adopted." ${ }^{1}$ This is despite the significant efforts made to improve the knowledge on neonatal drug therapy as evident by a 2-4 fold increase in hits in pubmed for search words newborn and drug / pharmacotherapy / pharmacokinetics. ${ }^{2}$

However, there is a gross discrepancy in the quantum of scientific output related to neonatal therapeutics between resource rich and limited countries. In this context, paper ${ }^{3}$ from Sri Lanka reporting on some aspects of neonatal therapeutics, published in this issue of JRCS, is commendable.

The paper describes few aspects of drug utilization pattern in 175 term neonates in a single hospital namely the type, extent and cost of drugs. Selection criteria are not reported. Recent concerns in neonatal therapeutics such as dose, off-label use, formulations, and excipients are not investigated in this paper. Though authors have further analysed antibacterial agents ( $A B A)$, results of antibactieral sensitivity tests are not reported. Data had been collected in early 2015 which need to be considered when interpreting the data on cost, choice of $A B A$ s and number of intravenous ABA units used.

In the study sample, gentamicin followed by surfactant and human immunoglobulin had accounted for $80 \%$ of the cost. Both surfactant and human immunoglobulin have specific indications and given either once or for a short duration whereas gentamicin is prescribed for any suspected sepsis and continued for a relatively longer period. According to paper using lower strength gentamicin $(20 \mathrm{mg} / 2 \mathrm{ml})$ as opposed to $80 \mathrm{mg} / 2 \mathrm{ml}$ was the reason for gentamicin accounting for the large slice of the budget. A total of 133 neonates (Table 3) have

Professor in Pharmacology and Specialist in Paediatrics, Department of Pharmacology, Faculty of Medicine, University of Colombo received 672 units of $20 \mathrm{mg} / 2 \mathrm{ml}$ gentamicin (unit price 505.58) costing 339749.76 (Table 5). The cost would be LKR 5322.24 if adult strength gentamicin (unit price LKR 7.92) had been used instead of paediatric strength. However, authors have commented "Even though it is a common practice, it cannot be recommended to use adult formulae instead of paediatric formulae (when it is available) as a cost saving measure, due to the higher chance of administrative errors especially in settings like NCUs".

Gentamicin dose for term neonates is $4-5 \mathrm{mg} / \mathrm{kg}$ every 24 hours (extended interval dose regimen by slow intravenous injection or intravenous infusion) or 2.5 $\mathrm{mg} / \mathrm{kg}$ every 12 hours (multiple daily dose regimens by slow intravenous injection). ${ }^{4}$ For neonatal sepsis, pharmacokinetic properties of a 'once a day' gentamicin regimen are shown to be superior to a 'multiple doses a day' regimen in that it achieves higher peak levels while avoiding toxic trough levels. ${ }^{5}$ In addition, gentamicin exhibits concentration dependent killing and has a relatively longer plasma elimination half-life in neonates. Because of these three key factors, newborns are given the required daily dose of gentamicin in single dose. Hence most of these neonates could have been treated with $4-5 \mathrm{mg} / \mathrm{kg} / 24$ hours, though the data about dose and frequency of administration are not available.

A hypothetical case of neonate weighing $2 \mathrm{~kg}$ requires a single daily dose of $10 \mathrm{mg}$. This is equivalent to $0.25 \mathrm{ml}$ in $80 \mathrm{mg} / 2 \mathrm{ml}$ preparation. Gentamicin comes in ampoules or vials as solution for injection. Using $1 \mathrm{ml}$ syringe, a volume of $0.25 \mathrm{ml}$ can be withdrawn accurately because this syringe is clearly calibrated in hundredths of a milliliter (one line represents $0.01 \mathrm{ml}$ ). Using this syringe a lowest dose of $2 \mathrm{mg}(0.05 \mathrm{ml})$ can be accurately withdrawn from an $80 \mathrm{mg} / 2 \mathrm{ml}$ gentamicin ampoule. This practice is adopted in many paediatric wards and in neonatal care units in Sri Lanka (personal communication). In my view, the expensive $20 \mathrm{mg} / 2 \mathrm{ml}$ gentamicin should be reserved only for extremely small neonates with very low weight who requires less than $2 \mathrm{mg}$ of gentamicin.

It is true that the gentamicin $20 \mathrm{mg} / 2 \mathrm{ml}$ vial is named as paediatric injection. The availability of this paediatric strength is mainly to avoid wastage of drug as the balance drug had to be discarded immediately. Disposing antibiotics into environment is a trigger factor for development of antibiotic resistance. Hence, having paediatric strength preparations will minimise the

https://orcid.org/0000-0003-0184-104X

This is an open-access article distributed under the terms of the Creative Commons Attribution License, which permits unrestricted use, distribution and reproduction in any medium, provided the original author and source are credited. 
amount of antibiotics that will be discarded after using a small amount for a neonate.

Ministry of Health, Sri Lanka has issued a circular that the recommendations given in the manufacturer's leaflet had to be followed with regard to reconstitution, storage and keeping the balance antibiotics (Personal communication). Hence, even a tiny amount of $4 \mathrm{mg}$ is used from the $80 \mathrm{mg}$ ampoule the balance can be discarded with not much of effect on the cost. However, in case of $20 \mathrm{mg}$ ampoule, the balance that should be discarded may be less than the $80 \mathrm{mg}$ ampoule, but economically has a greater effect considering the differences in the prices.

The paper states that 20 units of morphine sulphate had been used in 19 newborns (Table 3 and 5). Authors have not indicated the strength of morphine preparation used for neonates. As per the National drug estimate report of Pharmaceutical Items released by the Medical Supplies Division, there are two preparations of morphine (2 $\mathrm{mg} / 2 \mathrm{ml}$ or $15 \mathrm{mg} / 1 \mathrm{ml}$ ). Even with smaller strength, a volume of $0.1 \mathrm{ml}$ had to be administered for a baby of $1 \mathrm{~kg}$ (100 microgram/kg). Dosing errors in morphine will be fatal.

Hence using paediatric strength preparations should be enforced for drugs like morphine even if there is cost difference.

\section{References:}

1. Stiers JL, Ward RM. Newborns, one of the last therapeutic orphans to be adopted. JAMA Pediatr. 2014; 168:106-108

2. Allegaert A, van den Anker J. Clin Pharmacol Ther. 2015 September ; 98(3): 288-297

3. Gunawardane DA, Dharmaratne SD, Rowel DS. The pattern of drug use among term neonates and cost implications: Results from a study in a Sri Lankan neonatal care unit. Journal of Ruhunu Clinical Society. 2017,23,1: 8-13

4. Joint Formulary Committee. British National Formulary for children. London: BMJ Group and Pharmaceutical Press. 2017; (72)

5. Rao SC, Srinivasjois R, Moon K. One dose per day compared to multiple doses per day of gentamicin for treatment of suspected or proven sepsis in neonates. Cochrane Database of Systematic Reviews 2016, Issue 12. Art. No.: CD005091. DOI: 10.1002/14651858.CD005091.pub4. 